\title{
From board sports to board exams
}

\author{
Brad Ahrens, DVM, Laboratory Animal Resident \& PhD Candidate, \\ City of Hope \& University of Southern California, Los Angeles, CA
}

Dr. Ahrens reflects on his unique path toward a career in veterinary medicine and the personal insights and experiences that guided him along the way.

\section{What attracted you to animal medicine, after a childhood spent surfing and skateboarding in southern California? \\ I have always had an unwavering passion for both sports and animals. Growing up, everything I did in school revolved around my dream of becoming an "animal scien- tist," but I ended up focusing most of my time on sports. By the age of 12 I was spon- sored for skateboarding, and by 16 I was competing at the state level in multiple sports. In college I began to find my stride academically and, as team-sports became more time-consuming and board-sports ests. I focused on lab animal medicine and did whatever I could to gain experience with exotic and zoo animals on the side. In the end, my ambition afforded me the opportunity to demonstrate my abilities and earn my acceptance to a laboratory animal residency and $\mathrm{PhD}$ program and my current position as a zoo veterinarian. The greatest contributors to my success are the people who took risks and gave me a chance to show them what I could do, and my mom, who took away my skateboard whenever I got a $\mathrm{C}$ but was proud of me no matter what.} began to take a toll on my body, I realigned my priorities and began seeking opportunities to work with animals. I experimented with a variety of different animal career fields and I liked them all so much, I couldn't decide which to concentrate on! So, I headed off to veterinary school where I could get the necessary education to pursue a variety of options. One might think that, after spending much of my life in sports, it might be difficult to come home from work late each night and walk past racks of surfboards and skateboards, but it's easy for me because I have finally found my true calling working with animals and I wouldn't have it any other way.

\section{You work with a vast range of conventional and exotic species that are kept for research, exhibition and entertainment. What helped you get to where you are today?}

When I began my quest for the perfect animal career, I pictured myself ultimately working with exotic or zoo animals, and it wasn't until partway through veterinary school that I discovered the scarcity of opportunities in those fields. However, I am fortunate that I attended Western University, because their non-traditional curriculum allowed me to gain the necessary experience to pursue my unique inter-

Your current projects include research, teaching and public speaking. How do you balance these aspects of your professional life?

Balancing these endeavors is surprisingly manageable since they all complement each other. I love my research, and I am very passionate about what I do, which makes public speaking little more than an animated conversation about my own interests. Teaching is virtually no different, except that I don't always get to choose the topic. The challenge lies in allocating time and maintaining a balance among these activities. I am comically busy, but I adore teaching and inspiring people about the things I enjoy, so sacrificing a little sleep is well worth it. I believe that the key to research is collaboration and the key to success is support, so the more people I reach through in research.

You have already accomplished a great deal in your young career. What goals and ambitions do you have for your my talks, the greater my chances of success

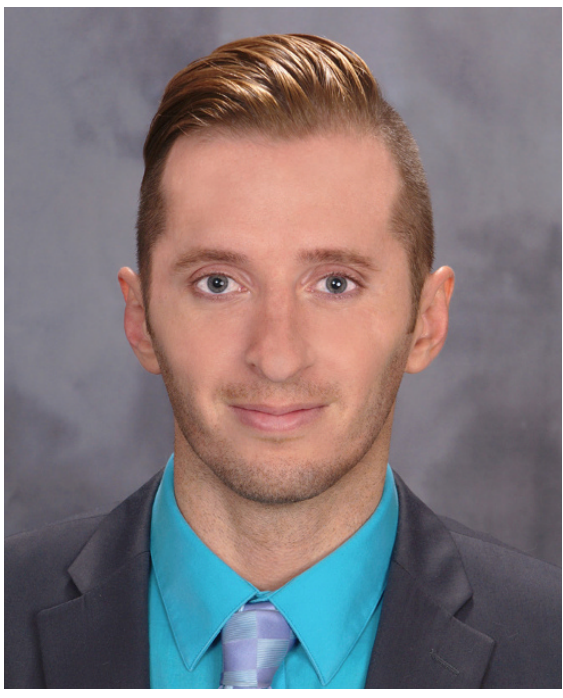

future in veterinary research and lab animal medicine?

My career goal is to become the director of comparative medicine or translational research at an institution where I can continue my own work, while using my unique experience and knowledge to maintain and improve the animal research program. I also hope to advance the research of exotic and less-studied species to discover new, optimal disease models and less-sentient alternatives to current standard animal models. Lastly, I would like to continue to work with zoos and wildlife organizations for the sake of conservation and discovery. I think many of the answers we are currently seeking in the lab have already been discovered and utilized by nature, and I'm hoping to help bridge the gap to discovering them.

You describe yourself as a specialist in 'exotic' or 'unusual' research animal models. Do you have a favorite (or least favorite) species?

My favorite animal model would probably be the tardigrade, or "water bear." With their little bear-shaped bodies, tiny claws and toothy suckers for faces, the cuteness factor is definitely there. They are also one of the toughest creatures on earth and there's a lot we can learn from them. My least favorite research animal would definitely be the hamster. They will always find a way to bite you. 